\title{
Obtain REMS Dispensing Authorization
}

National Cancer Institute

\section{Source}

National Cancer Institute. Obtain REMS Dispensing Authorization. NCI Thesaurus. Code C128516.

The dispenser must obtain authorization to dispense the drug from the REMS Program (e.g. over the phone, through a website, or electronically through a pharmacy management system). 